\title{
Dynamic and adaptive allocation of workers to integrate human factors into cyber production systems
}

\author{
Olha Kolesnyk ${ }^{1}$, Peter Bubeník ${ }^{1}$, Martin Gašo ${ }^{1}$, Ivan Antoniuk ${ }^{1}$ \\ ${ }_{1}$ University of Žilina, Faculty of Mechanical Engineering, Department of Industrial \\ Engineering \\ Univerzitná 8215/1, 01026 Žilina, Slovakia \\ olha.kolesnyk@fstroj.uniza.sk \\ peter.bubenik@fstroj.uniza.sk \\ martin.gaso@fstroj.uniza.sk \\ ivan.antoniuk@fstroj.uniza.sk
}

\begin{abstract}
Annotation: This article presents an adaptive, dynamic, and individualized method of staff allocation. The developed method is based on information about individual workers, a new flexible system of cyber-physical production, and communication between the participants of such a production system. According to the communication scenario, the requirements of the production flow and the production station are compared with the information about the employees. This provides the basis for the decision to assign staff. Workers are only assigned to production stations that match their qualifications and personal characteristics. For better integration of human factors into the CPPS, satisfaction with the work of each worker must also be taken into account. Therefore, a satisfaction value is defined for each production operation and production station and part of the employee information. The goal is to increase productivity in the production system and the satisfaction of each worker.
\end{abstract}

\section{Introduction}

In order to meet the challenges of globalized markets, shortened product life cycles and the growing demand for individualized products, the German federal government has launched the Industrie 4.0 initiative. The aim of this initiative is to achieve extremely flexible sectors, especially in high-wage countries. To this extent, research is carried out in cyber physical production systems (CPPS), in which cyber physics systems (CPS) consisting of sensors, actors and communication interfaces are implemented in production systems.

The main focus of CPPS is to enable the production of a large number of products in small sizes. A combination of automated and manual manufacturing operations is required to facilitate a highly flexible manufacturing process. However, manual production operations are strongly influenced by the individual professional knowledge and qualifications of each worker. 
Workforce management needs to be more flexible in order to predict order slippage and a wide variety of products. Instead of static prepayment, a dynamic allocation of workers is required, which takes into account several different factors, such as the individual qualifications and personal characteristics of each worker. For better integration of human factors into the CPPS, satisfaction with the work of each worker must also be taken into account.

\section{Cyber physical production system (CPPS)}

The basis of modern production systems are cybernetic systems. The principles of cyber physical systems defined by LEE are cyberization ofphysics and physicization of cybernetics. Everything that exists is physically represented in the virtual world, and everything that is represented practically exists in the physical world. [1]

Cybernetic systems are systems with embedded software. They are therefore an advancement in embedded systems. These computer systems use sensors to record data and influence physical processes by participants, evaluate and store data, interact with the physical and virtual worlds, interconnect, communicate through interfaces, use global data, and use human-machine interfaces.

Cyber physical production systems are used to equip production participants to acquire intelligent machines, storage systems and production facilities that are able to exchange information with each other, trigger actions and control each other. The Internet of Things and big data are two research areas in this context that are the result of the development of cyber systems. The Internet of Things is a network of all objects in an intelligent factory based on cybernetic systems. [1]

In ideal cyber production systems, all participants carry their own information. All production stations, workers and components in the production system are equipped with structured information storage. Each participant's information can be exchanged through the communication interfaces of cybernetic systems and can be used for autonomous decisions in the production process. Communication in a cyber physical production system can take place via a central server or directly between participants [2].

\section{Architecture of cyber physical production system}

Based on CPS technologies, there is a framework for a unified Cyber Physical e - commerce Logistics System (CPeLS) from real - time field data collection, through heterogeneous resource coordination and planning, to optimal supply chain synchronization decisions. [2]

The overall platform is built on a cloud architecture that enables three levels of cloud service: Infrastructure as a Service (laaS), Platform as a Service 
(PaaS), and Software as a Service (SaaS) Architecture of cyber physical production system is shown in Figure 1. Which enables the systematic integration, deployment and sharing of multiple technologies in logical layers. The implementation of enterprise information systems that comply with this standard hierarchy will ensure that the system is usable and extensible for companies. Seamless two-way connectivity and real-time interoperability can be achieved between enterprise, on-floor, work-cell, and loT application systems. The approach to creating a CPS-enabled business logistics platform is generally applicable when other management standards, strategies or facilities are adopted, whether or not they replace or complement existing solutions. [2]

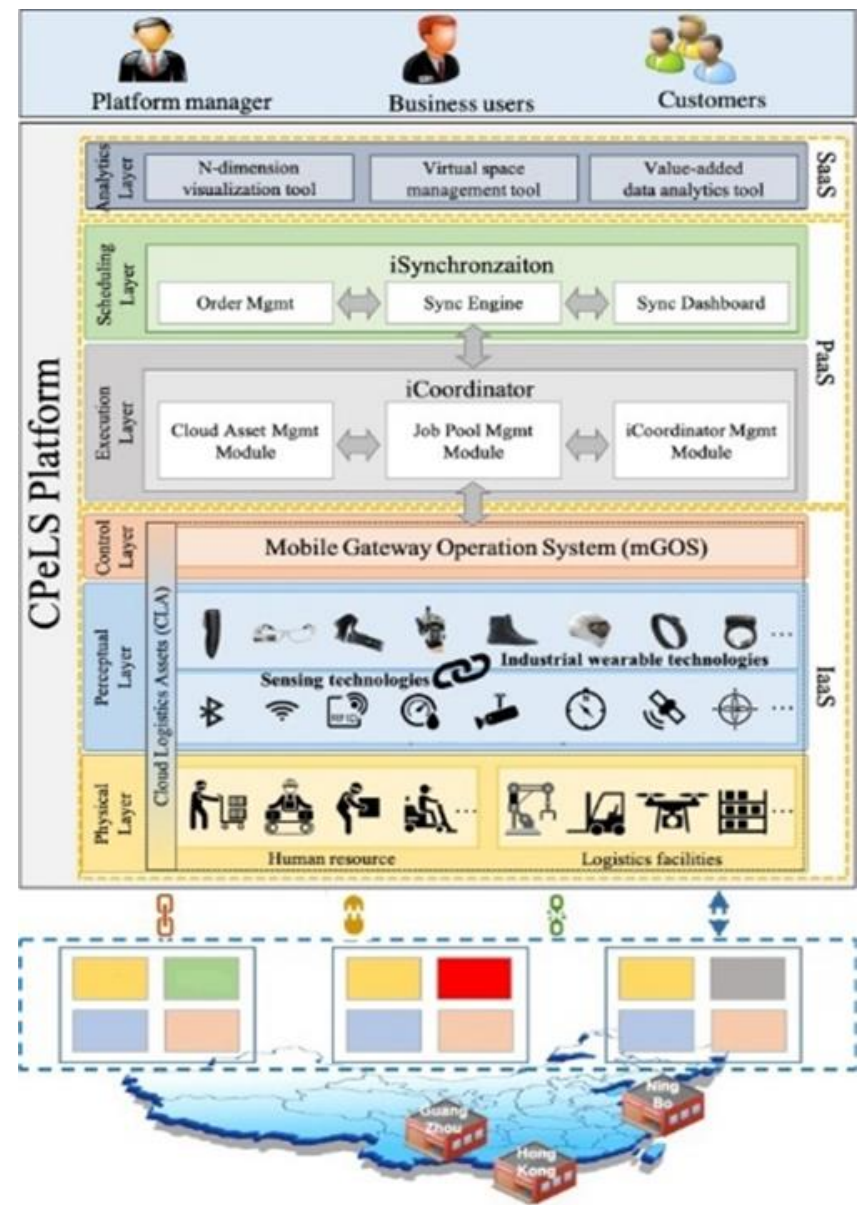

Figure 1 - The overall architecture of the logistics platform with CPS enabled [3]

At the laaS level, cloud logistics assets (CLAs) are the core technology for transforming physical logistics assets into virtualized cloud agendas. The basic element of the CLA is the Industrial Wearable Object (IWO), which combines sensing technologies with industrial wearable devices. MGOS (Mobile Gateway Operating System) is another basic technology for achieving virtualization of physical resources and for implementing intelligent management in the software aspect. [2]

At the PaaS level, the following two key components are included: 1 the intelligent coordination system (iCoordinator), as the main technology in the implementation layer, facilitates the execution of a synchronized order 
fulfillment process; 2 - an intelligent synchronization system (iSync), which works in the planning layer, is designed to solve synchronization problems in the logistics parks of the store. [3]

At the SaaS level, three services are included: 1 - different stakeholders provide a multi-dimensional visualization tool to control their related synchronization information; 2 - the virtual space management tool includes the concept of a "virtual enterprise" and coordinates different business logistics scenarios in distributed geographic locations with different business goals. CPeLS using standardized and open application programming interfaces. CPeLS also separates the operating environment for deploying prepaid services and provides a secure cloud for enterprise users. Third, the value-added data analysis tool stores theoretical and empirical models to optimize supply-side to demand-side processes. [3]

To ensure data security, all application program interface (API) calls in the proposed system are required to handle authentication. It can dynamically issue certificates to users, allowing them to log in to an active directory environment as if they had a smart card. In addition, information labels should be used so that the system can recognize the level of sensitivity of the data when used as output messages. [3]

\section{Dynamic and adaptive worker allocation}

Cyber production systems enable a new automatic form of staff allocation that is dynamic and adaptable. Dynamic allocation of staff is based on demand. This means that the production station requires a worker only when needed. The dynamic nature of the division of workers means that not all workers remain at one production station during one change, but are dynamically redistributed according to the requirements of production operations. [4]

A communication scenario is being developed to explain the concept of dynamic staff allocation in the CPPS. This communication scenario is shown in Figure 2. It is developed with a UML sequence diagram that defines the participants, communication and sequence of activities of each participant. In CPPS, components and production stations negotiate the execution of a production operation based on the individual information of the participants. Components carry a process plan that specifies all manufacturing operations. Each production operation has different requirements for the production station. Based on these requirements and the agreement between the components and the production stations, the corresponding station is automatically selected. [4] 


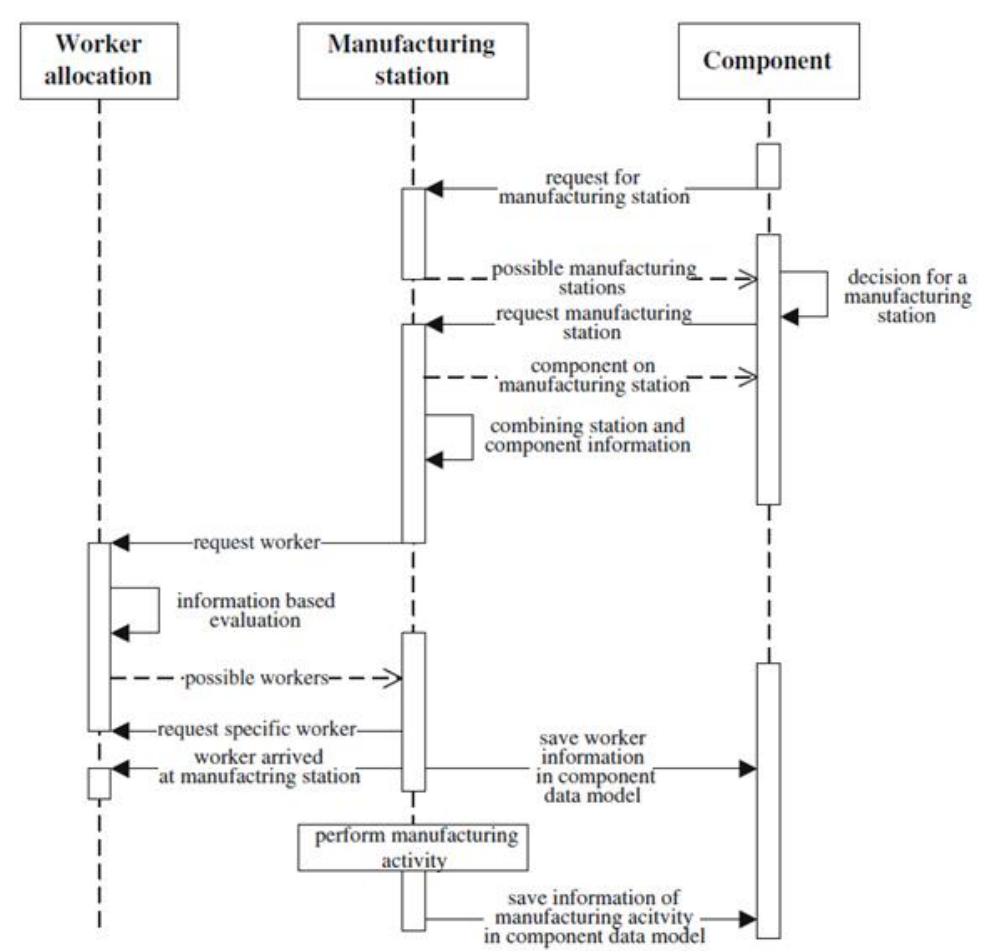

Figure 2 - Communication scenario for dynamic staff allocation [4]

Component and production station information is combined to specify requirements for the worker at the production station. The requirements are derived from this information. The production station requires a worker who meets the requirements. In the dynamic allocation of workers, the requirements are evaluated and potential workers are selected and the production station is informed about them. The production station selects one of the suitable workers. As soon as the required worker arrives at the production station, the production operation is performed. [4]

All communication activities in the communication scenario in Figure 2 must be represented in the data model. This is important to identify the reasons for the autonomous decision, to optimize the communication process, to update the information of each employee, production station and component, and to provide detailed service and customer documentation. [4]

The stored data of the component data model can be completely presented for internal problems and can be displayed with a limited amount of information for users. In order to preserve the privacy of CPPS employees, it is necessary to limit information. [4].

\section{$5 \quad$ Fixed and dynamic allocation of staff}

When using simulation, a number of workers with different qualifications are taken into account. Four use cases are defined for the implementation and validation of dynamic and adaptable staff allocation. The first use case is a fixed division of workers. Other use cases are defined to demonstrate 
the dynamic distribution of workers with different objectives. The principles of fixed and dynamic staff allocation are shown in Figure 3. [5].

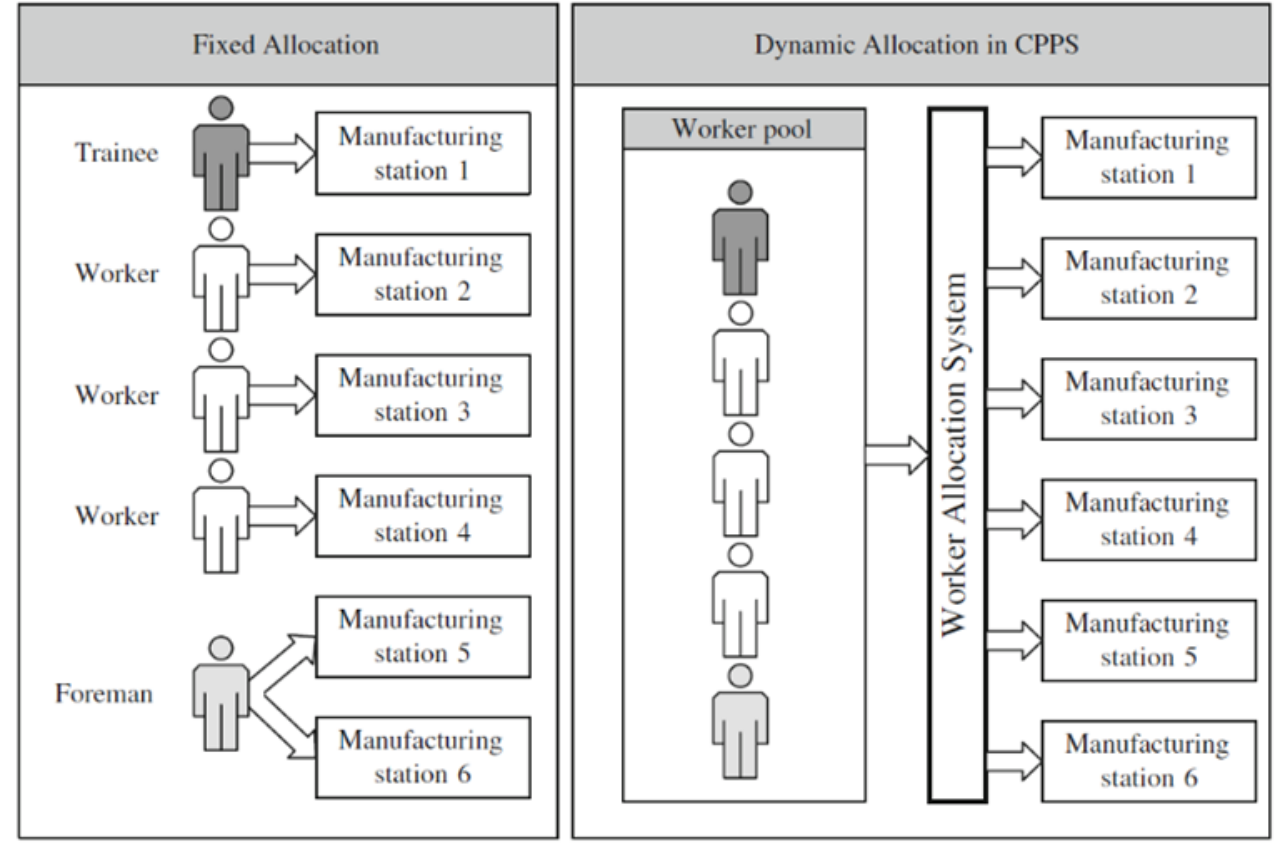

Figure 3 - Fixed and dynamic staff allocation [5]

Workers in the production system in Figure 3 are classified according to their qualifications. Trainee is a new employee at CPPS. He is not used to any of the production stations. Workers are average workers who have worked at CPPS for some time. They are familiar with some production stations and operations. Foreman is the person responsible for the assembly line. He therefore has a good knowledge of all production stations and production operations. [5]

\section{Conclusion}

Dynamic staff allocation for CPPS provides an approach to increase employee productivity and satisfaction through an individual profile model. By taking into account individual profile data, it is possible to optimize production time and the level of satisfaction. The ideal solution depends on the manufacturing company and lies somewhere between maximum productivity and maximum satisfaction.

Finally, the dynamic distribution of workers must be tested in a productive environment. The provision of individual profile data for each worker is currently not yet part of any production facility, but is the basis for the dynamic allocation of workers. Therefore, the dynamic distribution of staff can currently only be tested in research environments. 


\section{Acknowledgments}

This work was supported by the KEGA Agency under the contract no.: 022ŽU-4/2018.

\section{References}

[1] LEE, E. A. CPS foundations. In: Design Automation Conference (ACM), 2010, 737-742.

[2] GEISBERGER, E. M., BROY, M. Agenda CPS, Integrierte Forschungsagenda Cyber-Physical Systems. Springer: Berlin, 2012.

[3] KAGERMANN, H., WAHLSTER, W., HELBIG, J. Recommendations for implementing the strategic initiative INDUSTRIE 4.0. Securing the future of German manufacturing industry. Final Report of the Industrie 4.0 Working Group, Forschungsunion, 2013.

[4] KOPETZ, H. Internet of things. In: Real-time systems, Springer: Boston, 2011, 307-323.

[5] GELENBE, E., WU, F. J. Future research on cyber-physical emergency management systems. Future Internet, 2013, 5(3), 336-354.

[6] VAVRÍK, V. Projektovanie produkčných liniek s využitím princípov rekonfigurácie. Žilina, 2019. Diseratation thesis. University of Žilina. Faculty of Mechanical Engineering.

[7] FUSKO, M., BUČKOVÁ, M. Smart technologies in future factories. Technológ, 2019, 11(2), 79-84. ISSN 1337-8996. 